Journal of

Molecular Microbiology

and Biotechnology

\title{
Gene Expression and Biochemical Characterization of Azotobacter vinelandii Cyclophilins and Protein Interaction Studies of the Cytoplasmic Isoform with dnaK and IpxH
}

\author{
Maria Dimou Anastasia Venieraki Georgios Liakopoulos Evangelia D. Kouri \\ Anastasia Tampakaki Panagiotis Katinakis \\ Department of Agricultural Biotechnology, Agricultural University of Athens, Athens, Greece
}

\section{Key Words}

Azotobacter vinelandii $\cdot$ Chaperone $\cdot$ Cyclophilin $\cdot$ dnaK . Peptidyl-prolyl cis/trans isomerase $\cdot$ Protein interaction • RT-qPCR • UDP-2, 3-diacylglucosamine hydrolase

\begin{abstract}
The soil nitrogen-fixing bacterium Azotobacter vinelandii possesses two cyclophilins, comprising putative cytoplasmic and periplasmic isoforms, designated as AvPPIB and AvPPIA, respectively. Both recombinant cyclophilins have been purified and their peptidyl-prolyl cis/trans isomerase activity against Suc-Ala-Xaa-Pro-Phe-pNA synthetic peptides has been characterized. The substrate specificity of both cyclophilins is typical for bacterial cyclophilins, with Suc-Ala-Ala-Pro-Phe-pNA being the most rapidly catalyzed substrate. The cytoplasmic cyclophilin also displays a chaperone function in the citrate synthase thermal aggregation assay. Using real-time quantitative RT-PCR, we demonstrate that AvppiB is expressed under various physiological and growth conditions, mainly upregulated by acetate and downregulated by the stationary growth state, while AvppiA shows a tendency for downregulation under the tested conditions. Further, we identified chaperone protein dnaK and UDP-2, 3-diacylglucosamine hydrolase IpxH as probable
\end{abstract}

interacting partners of AvPPIB and we demonstrate their physical interaction by coexpression studies. An increase in AvPPIB PPlase activity in the presence of AvdnaK and a decrease in the presence of $A v l p x H$ further confirms each interaction. However, the PPlase activity does not seem to be essential for those interactions since AvPPIB active site mutants still interact with dnaK and IpxH, while their minor PPlase activity cannot be modulated by the interaction.

Copyright $\odot 2011$ S. Karger AG, Basel

\section{Introduction}

Amino acids are mainly connected in proteins via the trans peptide bond. The propensity for a cis peptide bond to exist in native proteins is $<0.1 \%$. However, in the case of the peptidyl-prolyl bond, the cis conformation increases from 5 to $6 \%$ in the native state [Jabs et al., 1999]. Spontaneous isomerization of peptidyl-prolyl bonds requires free energy and is a slow process which constitutes a ratelimiting step in protein folding. Peptidyl-prolyl cis/trans isomerases (PPIases, EC 5.2.1.8) catalyze this interconversion of peptidyl-prolyl bonds [Schmid, 1993] while they can also act on polypeptides as folding helper enzymes [Freeman et al., 1996; Rassow et al., 1995; Zarnt et

\section{KARGER}

Fax +41613061234 E-Mail karger@karger.ch www.karger.com

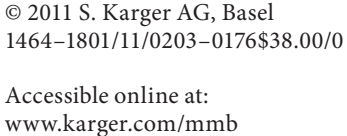


al., 1997]. The first type of this enzyme found proved to be the protein cyclophilin which binds the immunosuppressant cyclosporin A [Fischer et al., 1984]. Other distinct families of the enzyme exist, one being FK-506binding proteins and another that includes parvulins. These families are structurally unrelated and can be distinguished by being inhibited by cyclosporin A, FK-506 and 5-hydroxy-1, 4-naphthoquinone, respectively [Galat, 2003].

All cyclophilins share a common domain of approximately 109 amino acids, the cyclophilin-like domain, and are surrounded by domains unique to each member of the family that are associated with subcellular compartmentalization and functional specialization [Marks, 1996]. When the interaction with other proteins is not transient, these additional domains mediate a stable interaction [Schiene-Fischer and $\mathrm{Yu}, 2001]$. Besides mediating the cyclosporin A-induced immunosuppression, $c y-$ clophilins also participate in various cellular processes ranging from cell division, protein folding and regulation of HIV infection to several other important cellular steps [Baker et al., 1994; Baum et al., 2009; Braaten and Luban, 2001; Rassow et al., 1995]. Activities of various enzymes, transcription factors and heat shock proteins have also been shown to be modulated by binding with cyclophilins [Carrello et al., 2004; Jaschke et al., 1998; Lee et al., 2001].

Cyclophilins are ubiquitously distributed proteins, highly conserved during evolution and present in almost all organisms analyzed to date, with particular exceptions in bacteria such as Mycoplasma genitalium and some archaea [Göthel and Marahiel, 1999]. Although many of the eukaryotic cyclophilins have been studied extensively, few examples of functional characterization of these enzymes exist in prokaryotes, except Escherichia coli [Compton et al., 1992; Hayano et al., 1991; Liu and Walsh, 1990], Bacillus subtilis [Göthel et al., 1998], Streptomyces chrysomallus [Pahl et al., 1992; Pahl et al., 1997], Streptomyces antibioticus [Manteca et al., 2004], Legionella pneumophila [Schmidt et al., 1996] and Erwinia chrysanthemi [Pissavin and Hugouvieux-Cotte-Pattat, 1997]. The most obvious characteristic of bacterial cyclophilins is a lower affinity for cyclosporin A compared to human cyclophilin 18 (hCyp18) [Schönbrunner et al., 1991]. The cellular function of the bacterial homologues is still, however, poorly understood.

In this study, we describe the expression and purification of the recombinant Azotobacter vinelandii's cytoplasmic and periplasmic cyclophilins in E. coli and analyze their biochemical properties in vitro. We study the effect of different carbon sources, as well as the presence of ammonium in the growth medium, on both cyclophilins' gene expression, using RT-qPCR. Since it has been proposed that cyclophilins facilitate the peptidyl-prolyl isomerization of a trans-isomer to a cis-isomer in the refolding process of unfolded proteins [Konno et al., 2004], we considered proteins with cis-prolines to be some of the interacting candidates for them. We suggest the A. vinelandii $\mathrm{Hsp} 70$ chaperone protein dnaK (EC 3.6.3.51) to be such a protein and we demonstrate a stable in vivo interaction with the cytoplasmic cyclophilin $A v$ PPIB. Further, we identified UDP-2, 3-diacylglucosamine hydrolase lpxH (EC 3.6.1.B2) as a potential interacting partner of $A v \mathrm{PPIB}$ and we demonstrate their physical interaction by coexpression studies, as well. An increase in AvPPIB PPIase activity, in the presence of $A v \mathrm{dnaK}$ and a decrease in the presence of $A v l p x H$, further confirms each interaction. Finally, we demonstrate that the PPIase activity does not seem to be essential for these interactions since $A v$ PPIB active site mutants still interact with dnaK and lpxH, while their minor PPIase activity cannot be modulated by the interaction.

\section{Results}

AvppiB and AvppiA Encode Putative Cytoplasmic and Periplasmic Cyclophilins, Respectively

Using sequence homology searches, we identified two putative cyclophilins from $A$. vinelandii, AvPPIB (ACO78539) and $A v$ PPIA (ACO78121). A search for recognized protein motifs, using the Prosite database, revealed a cyclophilin-type peptidyl-prolyl cis/trans isomerase signature at amino acids $36-53$ of $A v$ PPIB and at amino acids $60-77$ of $A v$ PPIA. Comparison of the predicted amino acid sequences of both proteins with other proteins in the public databases revealed that they show similarity to other cyclophilins from different organisms. $A v$ PPIB shows an overall $64 \%$ identity with cytoplasmic ppiB from $E$. coli, while $A v$ PPIA shows an overall $66 \%$ identity with periplasmic ppiA from E. coli and is predicted to have a periplasmic localization using the PSORT-B program (http://www.psort.org/psortb/). Further, SignalP program (http://www.cbs.dtu.dk/services/ SignalP/) predicted a signal peptide probably consisting of the first 33 amino acids of $A \nu$ PPIA. Figure 1 shows the amino acid sequence alignment of $A v$ PPIB and $A v$ PPIA with representative cyclophilins from bacteria as well as with cypA from Homo sapiens. 


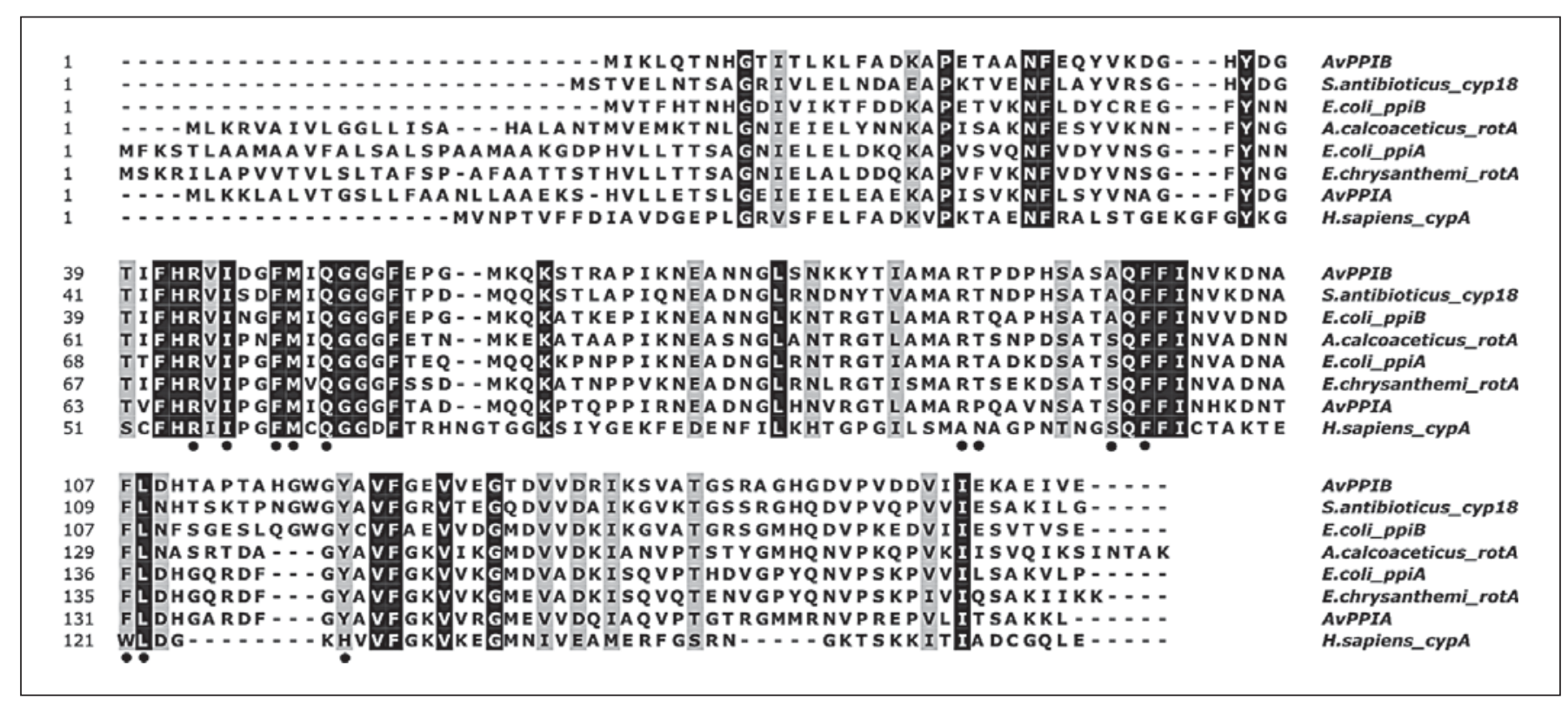

Fig. 1. Sequence alignment of $A v$ PPIB (ACO78539), $A v$ PPIA (ACO78121) and related cyclophilins. The sequences included are H. sapiens cypA (P05092), Acinetobacter calcoaceticus rotA (CAA52834), E. chrysanthemi rotA (CAA70935), S. antibioticus cyp18 (AAQ88274), E. coli ppiB (P23869) and E. coli ppiA

\section{Recombinant AvPPIB and AvPPIA Have}

Peptidyl-Prolyl Cis/Trans Isomerase Activity

To elucidate whether $A v$ PPIB and $A v$ PPIA are active as peptidyl-prolyl cis/trans isomerases, both genes were cloned from $A$. vinelandii and fused to an expression vector to obtain the corresponding His-tagged proteins, which were overproduced in E. coli BL21 (DE3) cells and purified using Ni-NTA chromatography (fig. 2c, 3c). The purified fractions were applied to the standard PPIase assay utilizing isomer-specific proteolysis by chymotrypsin. The elution fraction from Ni-NTA purification, using E. coli BL21 (DE3) cells overexpressing pET28a vector only, was used in control reactions.

The assay for PPIase activity is based on the conformational specificity of chymotrypsin, which cleaves the 4-nitroanilide moiety from succinyl-Ala-Xaa-Pro-Phe-4nitroanilides only when the Xaa-Pro peptide bond is in the trans conformation. In the presence of PPIases, the Xaa-Pro bond is more rapidly converted to the trans conformation, which is readily cleaved by chymotrypsin leading to the formation of the colored product 4nitroaniline [Kofron et al., 1991]. Kinetic data were obtained in the presence of increasing amounts of (His) ${ }_{6}$ $A v$ PPIB and (His) ${ }_{6}-A v$ PPIA, and the differences between
(P0AFL3). Multiple sequence alignment was performed using ClustalW [Chenna et al., 2003]. Black boxes indicate identical amino acids while grey boxes indicate similar ones. Amino acid residues involved in substrate binding of $H$. sapiens cypA (black dots) [Kallen and Walkinshaw, 1992] are indicated. the isomerization rate constants $k_{\mathrm{obs}}$ and $k_{\mathrm{o}}$ (referring to the catalyzed and uncatalyzed reactions, respectively) were plotted as a function of protein concentration (fig. 2a, 3a). The slope of the resultant line is equivalent to the specificity constant $k_{\text {cat }} / K_{\mathrm{m}}$ (fig. $2 \mathrm{~b}, 3 \mathrm{~b}$ ).

The substrate specificity for both proteins was determined. The highest $K_{c a t} / K_{m}$ for both enzymes was demonstrated for the substrate peptide where alanine preceded the proline residue (table 1). In addition, the substrate specificity was not restricted to alanine preceding the proline residue since both cyclophilins showed specificity for phenylalanine and leucine as well, although in lower levels (table 1).

\section{Recombinant AvPPIB Has Chaperone Activity}

To monitor the possible chaperone activity of $A \nu \mathrm{PPIB}$ and $A v$ PPIA, the citrate synthase aggregation assay was used [Buchner et al., 1998]. At temperatures above $37^{\circ} \mathrm{C}$, citrate synthase loses its native conformation and undergoes spontaneous aggregation. AvPPIB was able to suppress thermal aggregation of citrate synthase when added in an equimolar concentration to the assay mixture (fig. 4). On the contrary, $A v$ PPIA does not seem to be a chaperone because citrate synthase aggregation could not 
Fig. 2. Enzymatic measurements of the PPIase activity of the purified $A \nu$ PPIB. a Hydrolysis of the peptide Suc-AAPFpNA by $\alpha$-chymotrypsin in the absence and presence of $A v$ PPIB at $1 \mathrm{nM}, 2.5 \mathrm{nM}$, $5 \mathrm{nM}, 7.5 \mathrm{nM}$ and $10 \mathrm{nM}$ concentrations. The background absorbance of $p$-nitroaniline release is due to the initial presence of the trans form of Suc-AAPF-pNA. The results are representative of three series of measurements. b Dependence of the isomerization rate constant on the $A v$ PPIB concentration. Each point is represented as the mean \pm SE of three determinations. c SDS-PAGE analysis of the soluble cytoplasmic fraction from E. coli BL21 (DE3) cells overexpressing $A v$ PPIB (lane a), the flow through fraction after the Ni-NTA purification (lane b) and the elution fraction after the Ni-NTA purification of the recombinant $A v \mathrm{PPIB}$ (lane c).

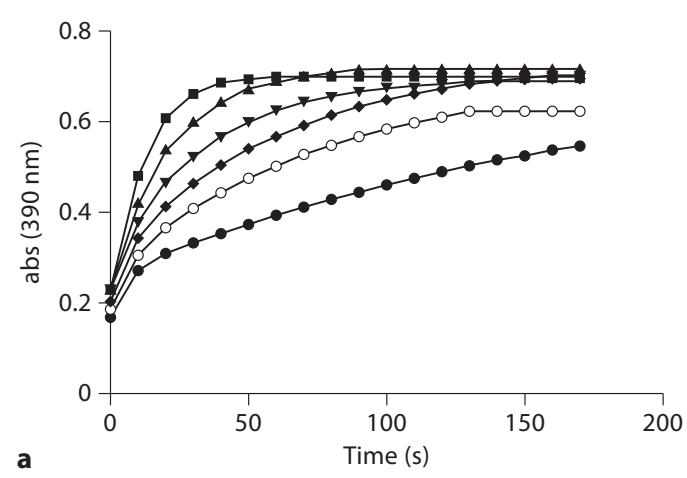

- $0 \mathrm{M}$ AvPPIB

- $1.0 \mathrm{nM}$ AvPPIB

- $2.5 \mathrm{nM}$ AvPPIB

$5.0 \mathrm{nM}$ AvPPIB

$\triangle 7.5 \mathrm{nM}$ AvPPIB

- $10 \mathrm{nM}$ AvPPIB

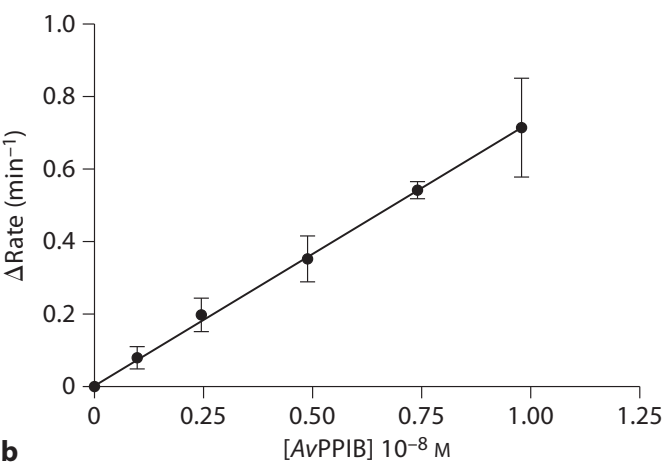

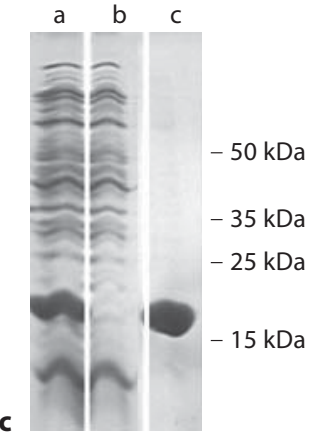

Table 1. Two substrate specificities of $A v$ PPIB and $A v$ PPIA

\begin{tabular}{lll}
\hline Substrate (-Xaa-) & \multicolumn{2}{l}{$\mathrm{K}_{\text {cat }} / \mathrm{K}_{\mathrm{m}}\left(\mu \mathrm{M}^{-1} \mathrm{~s}^{-1}\right)$} \\
\cline { 2 - 3 } & $\mathrm{AvPPIB}$ & AvPPIA \\
\hline -Ala- & $1.201 \pm 0.064$ & $0.554 \pm 0.028$ \\
-Phe- & $0.272 \pm 0.018$ & $0.053 \pm 0.005$ \\
-Leu- & $0.016 \pm 0.001$ & $0.052 \pm 0.004$ \\
\hline
\end{tabular}

PPIase activity was determined at $390 \mathrm{~nm}$ with the isomer specific proteolytic assay at $4^{\circ} \mathrm{C}$ in $50 \mathrm{~mm}$ Hepes $\mathrm{pH}(8.0), 70 \mathrm{~mm}$ $\mathrm{NaCl} . K_{\text {cat }} / K_{m}$ is given in $\mu \mathrm{M}^{-1} \mathrm{~s}^{-1}$.

-Xaa- represents various amino acids of substrates with the general sequence suc-A-Xaa-PF-pNA.

be suppressed, even when $A v$ PPIA was added in high excess (fig. 4; data not shown). Under the same assay conditions but without citrate synthase addition, $A v$ PPIB remained stable while $A v$ PPIA lost its conformation and aggregated as well, indicating the need for further studies before a final conclusion of the enzyme characteristics is considered. At control reactions, addition of $50 \mu \mathrm{M}$ of PDI efficiently prevents citrate synthase aggregation, while addition of up to $50 \mu \mathrm{M}$ of BSA has no effect. Further, there was no effect with addition of the elution fraction after the Ni-NTA purification using E. coli BL21 (DE3) cells overexpressing pET28a vector only.

\section{Oligomeric State Analysis of Recombinant AvPPIB and $A v P P I A$}

In order to gain insight into the oligomeric state of recombinant $A v$ PPIB and $A v$ PPIA, we performed gel filtration analysis. The recombinant $A \nu \mathrm{PPIB}$ was estimated as an approximate $18-\mathrm{kDa}$ peak being close to the theoretical molecular mass of $A \nu \mathrm{PPIB}$, which is approximately 21 $\mathrm{kDa}$. Similarly, recombinant $A \nu$ PPIA was estimated as an approximate $18-\mathrm{kDa}$ peak being close to the theoretical molecular mass of $A \nu$ PPIA, which is approximately 19 $\mathrm{kDa}$.

\section{Effect of Carbon and Ammonium Source and Growth \\ Phase on AvppiB and AvppiA Expression}

The influence of growth phase (exponentially or stationary grown cells), carbon source (acetate or glucose) and source of fixed nitrogen (ammonium supplied either by nitrogen fixation or exogenously supplied to the medium) on the relative expression levels of the two cy- 
Fig. 3. Enzymatic measurements of the PPIase activity of the purified AvPPIA. a Hydrolysis of the peptide Suc-AAPFpNA by $\alpha$-chymotrypsin in the absence and presence of $A v$ PPIA at $6 \mathrm{nM}, 12 \mathrm{nM}$, $17.5 \mathrm{nM}, 24 \mathrm{nM}, 29 \mathrm{nM}$ and $35 \mathrm{nM}$ concentrations. The background absorbance of $p$ nitroaniline release is due to the initial presence of the trans form of Suc-AAPFpNA. The results are representative of three series of measurements. b Dependence of the isomerization rate constant on the $A v$ PPIA concentration. Each point is represented as the mean \pm SE of three determinations. c SDS-PAGE analysis of the soluble cytoplasmic fraction from E. coli BL21 (DE3) cells overexpressing $A \nu$ PPIA (lane a), the flow through fraction after the Ni-NTA purification (lane b) and the elution fraction after the Ni-NTA purification of the recombinant $A v$ PPIA (lane c).

Fig. 4. Influence of $A v \mathrm{PPIB}$ and $A v \mathrm{PPIA}$ on the thermal aggregation of citrate synthase. Citrate synthase was incubated at $45^{\circ} \mathrm{C}$. Aggregation was monitored by measuring the turbidity of the solution at $500 \mathrm{~nm}$ in the absence and the presence of additional components. Aggregation of $0.25 \mu \mathrm{M}$ citrate synthase in the absence of additional components and in the presence of $0.25 \mu \mathrm{M} A v$ PPIB and $0.25 \mu \mathrm{M} A v$ PPIA. Control reactions were performed in the presence of $50 \mu \mathrm{M}$ PDI and in the presence of $50 \mu \mathrm{M}$ BSA. The results are representative of three series of measurements performed with different preparations of $A v$ PPIB and $A v$ PPIA.

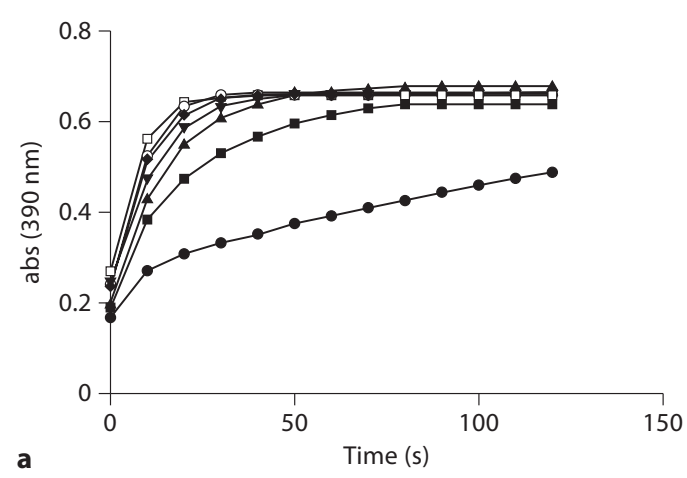

- 0 M AvPPIA

- 6 nM AvPPIA

- 12 nM AvPPIA

$\checkmark 17.5 \mathrm{~nm}$ AvPPIA

- 24 nM AvPPIA

- 29 nM AvPPIA

口 $35 \mathrm{~nm}$ AvPPIA
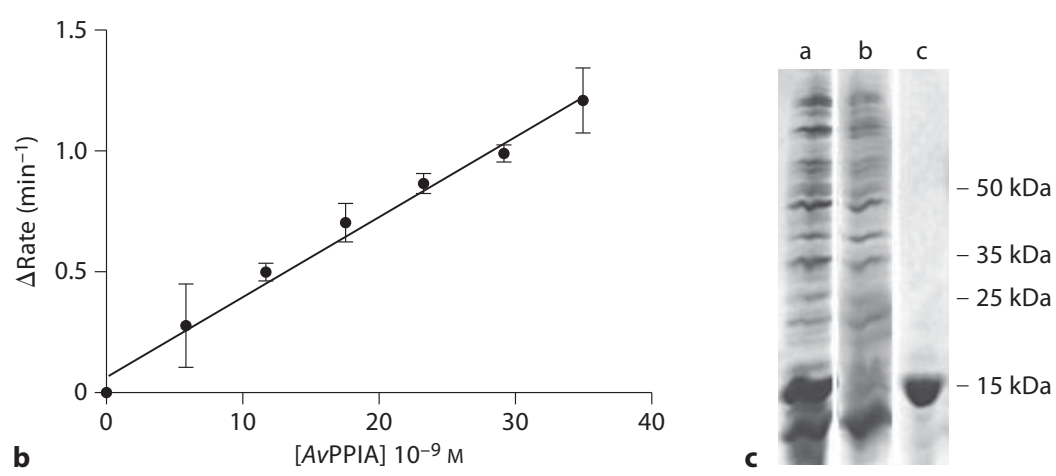

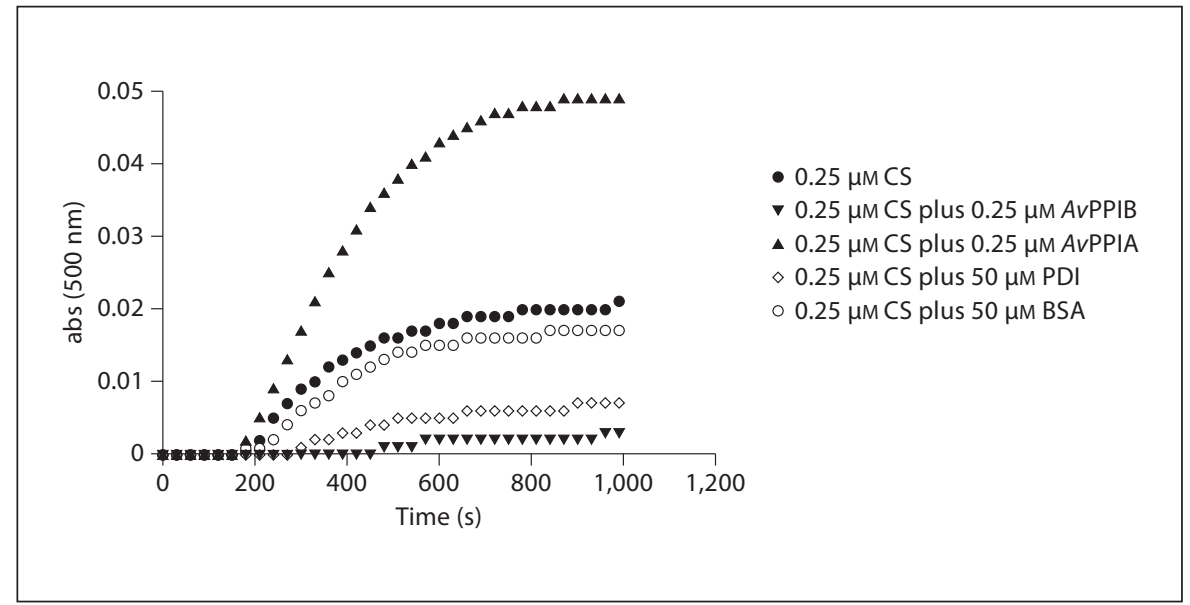

clophilin genes was examined by measuring the accumulation of their gene transcripts using real-time RT-qPCR. Cells from the exponential and the stationary phases were harvested and the relative gene expression levels were calculated against LB full medium grown cells from the same developmental phases. For normalization, recA (Avin_38560) was used as a reference gene.
The presence of ammonium in the acetate-containing medium increased about threefold the relative expression ratio of $A v p p i B$, while in all other tested conditions, $A v p p i B$ was downregulated or not significantly upregulated (fig. 5a). AvppiA, on the other hand, shows a tendency for downregulation, with no significant differences among the exponential and the stationary phase, in both nitrogen-fixing and nonfixing conditions (fig. 5b). 


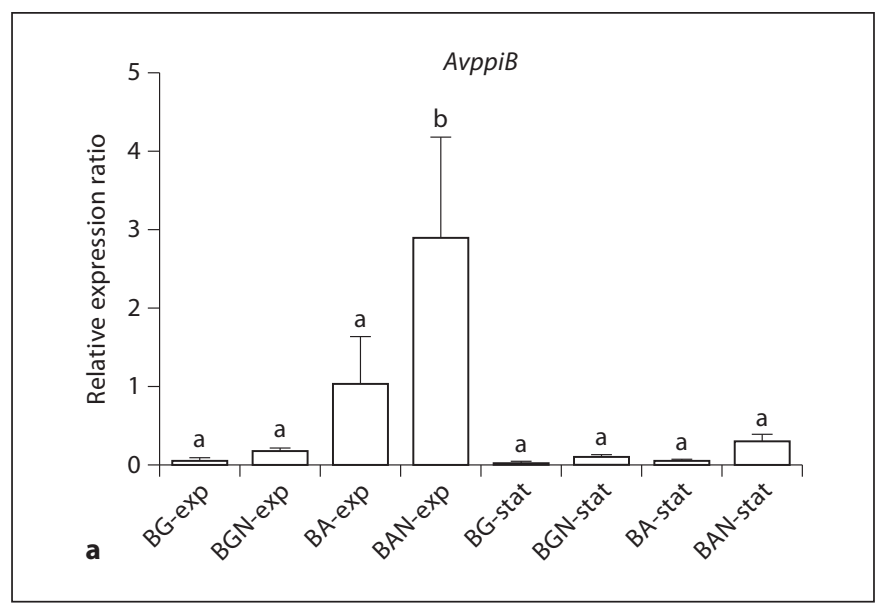

Fig. 5. Relative expression levels of $A v p p i B$ and $A v p p i A$ in A. vinelandii cultures grown in various Burk's minimal media (BG: Burk's with glucose, BGN: Burk's with glucose and ammonium, BA: Burk's with acetate, BAN: Burk's with acetate and ammonium) vs. A. vinelandii cultures grown in LB full medium as determined by RT-qPCR. Fold change was calculated according to the equation described in the Materials and Methods, with normal-

\section{AvdnaK and AvlpxH as Probable Interacting \\ Candidate Proteins for AvPPIB}

The application of high-throughput technologies, such as large-scale yeast two-hybrid or affinity purification analyses, has generated a vast amount of data that have allowed the construction of many protein-protein interaction databases. In an attempt to perform a predictive analysis of the interaction network for the $A$. vinelandii cyclophilins, we searched the IntAct database [Hermjakob et al., 2004] and particularly the E. coli protein interaction data sets [Arifuzzaman et al., 2006; Butland et al., 2005]. Among all the probable preys, we inferred proteins with cis-prolines to be the most evident ones and considered them as the initial base of our study.

Searching the literature as well as the PDB database for homologous structures with cis-prolines, we noticed that in 1 bpr and $1 \mathrm{dg} 4$ entries, representing structures of the substrate binding domain of the Hsp70 chaperone protein dnaK from E. coli, Pro $^{419}$ adopts the cis configuration [Wang et al., 1998]. Further, Vogel et al. [2006] proposed that Pro $^{143}$ in the ATPase domain constitutes a switch in mutual allosteric control between ATPase domain and substrate binding domain of dnaK, likely involving a cis/ trans transition. These two proline residues remain conserved in A. vinelandii and other bacterial dnaKs; there-

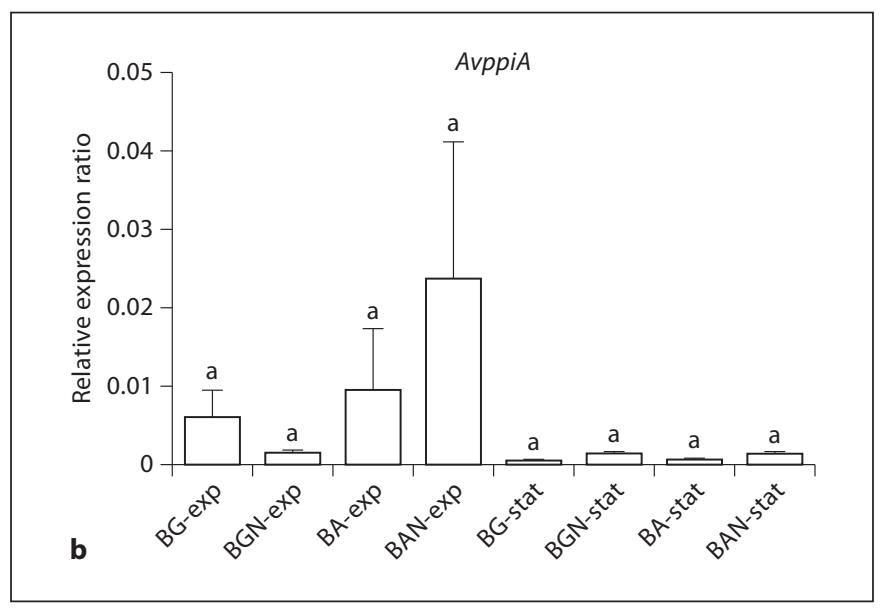

ization against $\operatorname{rec} A$. The data are the mean of three biological replications while the bars represent standard errors. ${ }^{a}$ Nonsignificant difference $(\mathrm{p}>0.05) ;{ }^{\mathrm{b}}$ significant difference $(\mathrm{p}<0.05)$ calculated by ANOVA followed by Tukey's multiple comparison test using GraphPad Prism v5.0 (GraphPad Software, San Diego, Calif., USA).

fore, we considered $A v \mathrm{dnaK}$ as a good interacting candidate protein for $A \nu$ PPIB.

Further, using Pfam searches, we found that the Avin_23500 gene coding for a putative UDP-2, 3-diacylglucosamine hydrolase, located adjacent to Avin_23510 coding for $A \nu \mathrm{PPIB}$, belongs to the calcineurin-like phosphoesterase family (PF00149). Since immunophilins are able to interact with calcineurin in the absence of exogenous immunosupressive ligands and modulate its phosphatase activity [Cardenas et al., 1994], we hypothesized that such an interaction might be conserved among other members of the calcineurin-like phosphoesterase family as well. Therefore, we considered UDP-2, 3-diacylglucosamine hydrolase $A v \mathrm{lpxH}$ as a potential interacting candidate protein for $A \nu \mathrm{PPIB}$.

\section{AvPPIB Physically Interacts with AvdnaK or AvlpxH}

In order to confirm our hypotheses, we tested whether $A v$ PPIB interacts with $A v$ dnaK or $A v l$ pxH in vivo. We independently coexpressed $A v$ PPIB with $A v$ dnaK or $A v l p x H$, as two separate polypeptides, with a (His) ${ }_{6}$-tag fused at the N-terminus of $A \nu$ PPIB and an S-tag fused at the C-terminus of $A v \mathrm{dnaK}$ or $A v \mathrm{lpxH}$, using the pCDFDuet-1 vector. The soluble coexpressed proteins were purified under native conditions using Ni-resin affinity chromatography, indicating that each protein pair forms 


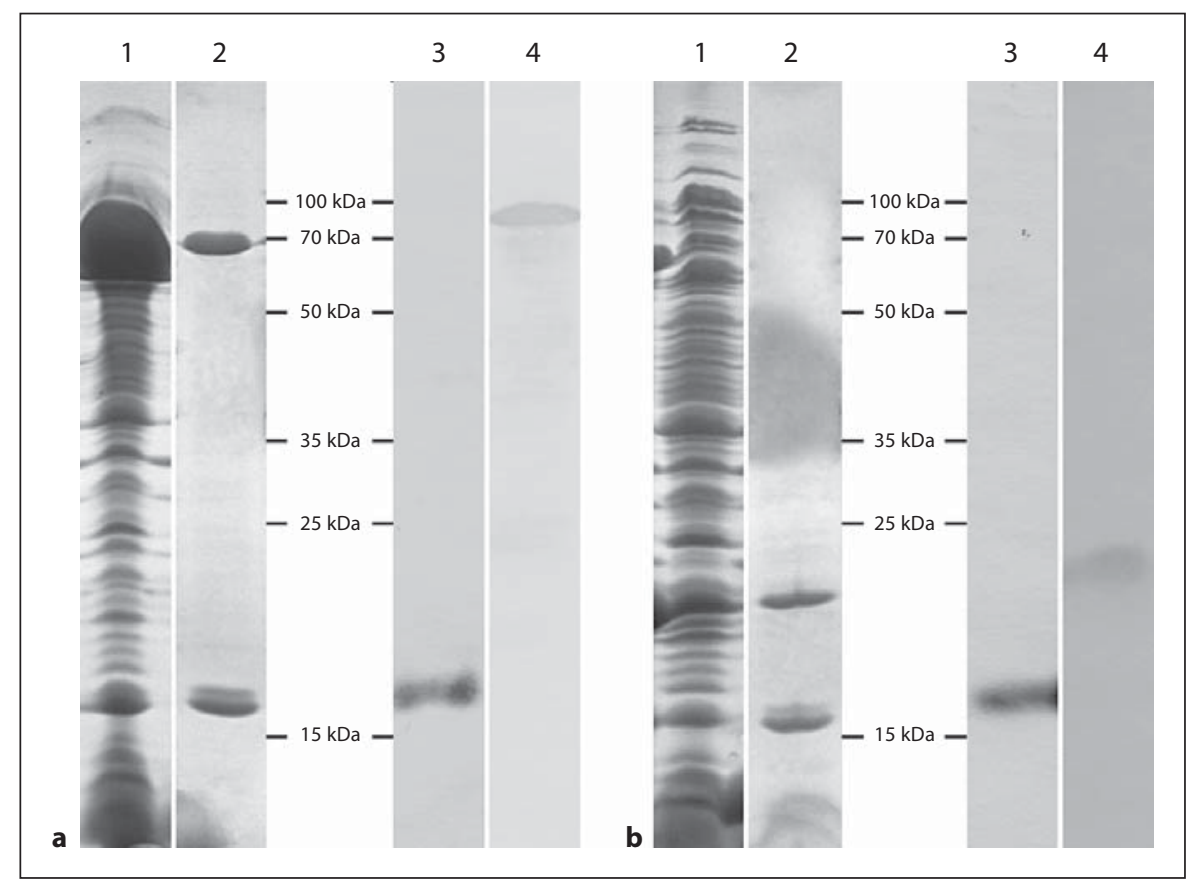

Fig. 6. Molecular interaction between $A v$ PPIB and $A v$ dnaK or $A v$ lpxH. a SDS-PAGE analysis of the soluble cytoplasmic fraction from $E$. coli BL21 (DE3) cells overexpressing AvPPIB-AvdnaKpCDFDuet1 (lane 1) and the elution fraction after the Ni-NTA purification of the $A v \mathrm{PPIB}-A v \mathrm{dnaK}$ protein complex (lane 2). Western blot analysis using His-tag specific antibodies of the elution fraction after the Ni-NTA purification of the AvPPIB$A v$ dnaK protein complex (lane 3 ). Western blot analysis using Stag specific antibodies of the elution fraction after the Ni-NTA purification of the recombinant $A v \mathrm{PPIB}-A v$ dnaK protein com- plex (lane 4). b SDS-PAGE analysis of the soluble cytoplasmic fraction from E. coli BL21 (DE3) cells overexpressing AvPPIB$A v$ lpxH-pCDFDuet1 (lane 1) and the elution fraction after the Ni-NTA purification of the $A v$ PPIB- $A v$ lpxH protein complex (lane 2). Western blot analysis using His-tag specific antibodies of the elution fraction after the Ni-NTA purification of the $A \nu \mathrm{PPIB}-A v \mathrm{lpxH}$ protein complex (lane 3 ). Western blot analysis using S-tag specific antibodies of the elution fraction after the $\mathrm{Ni}$ NTA purification of the recombinant $A v$ PPIB- $A v$ lpxH protein complex (lane 4). a stable complex. The existence of both polypeptides was confirmed by SDS-PAGE and immunoblotting with antibodies against the His and S-tags (fig. 6). Control experiments were performed where just S-tag fused $A v$ dnaK or $A v l p x H$ was not retained by the Ni-NTA agarose column. Any minor fractions of other molecular weights represent $E$. coli proteins retained by the Ni-agarose since the elution fraction after the Ni-NTA purification using E. coli BL21 (DE3) cells overexpressing pCDFDuet-1 vector only was used as a control.

When we coexpressed the two protein pairs from pACYCDuet-1, a lower copy number vector, the respective proteins continued to interact. Furthermore, in order to further lower the concentration of the coexpressed proteins, demonstrating the specificity of the binding assay, we decreased the final isopropyl 1-thio- $\beta$-D-galactopyranoside concentration to $0.1 \mathrm{mM}$ than the previously used $0.5 \mathrm{mM}$. In all cases, the respective protein pairs continued to interact.

\section{AvdnaK and AvlpxH Modulate AvPPIB Activity}

To verify the binding of $A v$ PPIB to $A v \mathrm{dnaK}$ or $A v \mathrm{lpxH}$, the effect of $A v \mathrm{dnaK}$ or $A v \mathrm{lpxH}$ on the PPIase activity of $A v$ PPIB was determined using the standard PPIase assay utilizing isomer-specific proteolysis by chymotrypsin [Kofron et al., 1991]. Both AvdnaK and AvlpxH genes were overexpressed in E. coli BL21 (DE3) cells producing Histagged recombinant proteins which were purified using Ni-NTA chromatography. Kinetic data were obtained in the presence of $A v \mathrm{PPIB}$ and the difference between the isomerization rate constants $k_{\mathrm{obs}}$ and $k_{\mathrm{o}}$, referring to the catalyzed and uncatalyzed reactions respectively, was determined. 
Fig. 7. Effect of $A v \mathrm{dnaK}$ and $A v \operatorname{lpxH}$ on $A v$ PPIB PPIase activity. a PPIase activity of $60 \mathrm{nM} A v \mathrm{PPIB}$ in the presence of $60 \mathrm{nM}$ and $600 \mathrm{~nm} A v$ dnaK. b PPIase activity of $60 \mathrm{~nm}$ $A \nu \mathrm{PPIB}$ in the presence of $60 \mathrm{nM}, 600 \mathrm{nM}$ and $1.2 \mu \mathrm{M} A v \mathrm{lpxH}$. Mean values were obtained from three independent replicates and error bars represent standard errors. Statistical comparisons were made using a one-way ANOVA followed by Dunnett's multiple comparison test. Asterisks indicate a statistically significant difference $(\mathrm{p}<0.05)$.

Fig. 8. Influence of $A v \mathrm{PPIB}_{\mathrm{F} 99 \mathrm{~A}}$ and $A v \mathrm{PPIB}_{\mathrm{R} 43 \mathrm{~A}}$ on the thermal aggregation of citrate synthase. Citrate synthase was incubated at $45^{\circ} \mathrm{C}$. Aggregation was monitored by measuring the turbidity of the solution at $500 \mathrm{~nm}$ in the absence and presence of additional components. a Aggregation of $0.25 \mu \mathrm{M}$ citrate synthase in the absence of additional components and in the presence of $0.25 \mu \mathrm{M} A \nu \mathrm{PPIB}_{\mathrm{F} 99 \mathrm{~A}}$, $0.75 \mu \mathrm{M} A \nu \mathrm{PPIB}_{\mathrm{F} 99 \mathrm{~A}}$ and $2 \mu \mathrm{M} A \nu \mathrm{PPIB}_{\mathrm{F} 99 \mathrm{~A}}$. b Aggregation of $0.25 \mu \mathrm{M}$ citrate synthase in the absence of additional components and in the presence of $0.25 \mu \mathrm{M}$ $A v \mathrm{PPIB}_{\mathrm{R} 43 \mathrm{~A}}, 0.75 \mu \mathrm{M} A \nu \mathrm{PPIB}_{\mathrm{R} 43 \mathrm{~A}}$ and $2 \mu \mathrm{M}$ $A v \mathrm{PPIB}_{\mathrm{R} 43 \mathrm{~A}}$. The results are representative of three series of measurements performed with different preparations of $A v \mathrm{PPIB}_{\mathrm{F} 99 \mathrm{~A}}$ and $A v \mathrm{PPIB}_{\mathrm{R} 43 \mathrm{~A}}$.
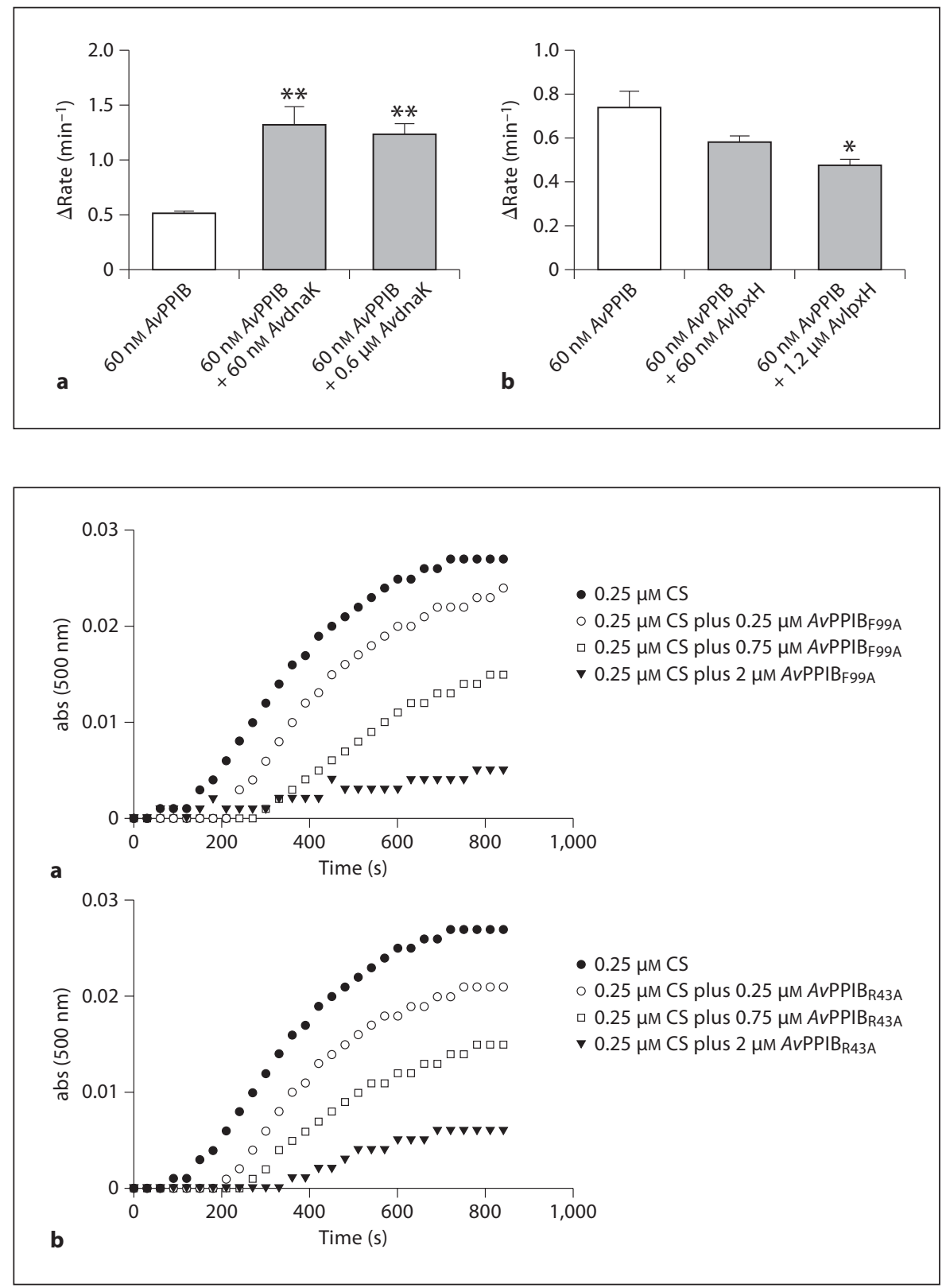

When we added $A v$ dnaK to the reaction containing 60 nM $A v \mathrm{PPIB}$, we observed an increase in activity, up to approximately $255 \%$ of the control reaction when $A v$ dnaK was added in $1 \times$ molar excess over AvPPIB ( $\mathrm{p}<0.05$; fig. 7a). When we added $A v \operatorname{lpxH}$ to the reaction containing $60 \mathrm{nM} A v \mathrm{PPIB}$, we observed a concentration-dependent decrease in activity, up to approximately $64 \%$ of the control reaction when $A \nu$ PTA- 1 was added in $20 \times$ molar excess over $A v$ PPIB ( $\mathrm{p}<0.05$; fig. $7 \mathrm{~b}$ ). Addition of BSA had no effect on PPIase activity, while $A v$ dnaK or $A v l p x H$ alone did not show any PPIase activity.

\section{$A v P P I B_{F 99 A}$ and $A v P P I B_{R 43 A}$ Point Mutants Lack}

PPIase Activity but Retain Some Chaperone Activity

To examine the role of PPIase activity in $A v$ PPIB function, we introduced active-site mutations and addressed the in vitro enzymatic activities of the mutant enzymes. $\mathrm{Phe}^{99}$ and $\mathrm{Arg}^{43}$ residues (A. vinelandii numbering) in- 


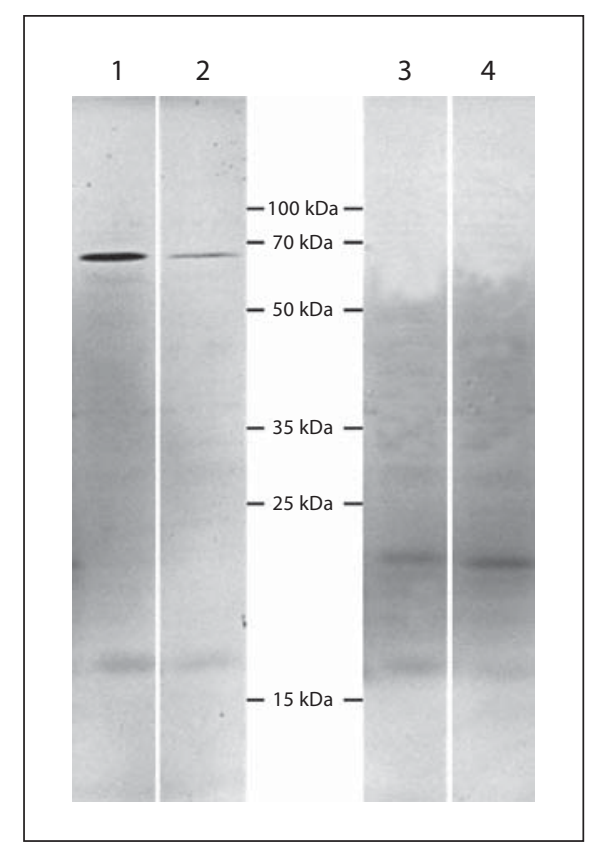

Fig. 9. Molecular interaction between $A v \mathrm{PPIB}_{\mathrm{F} 99 \mathrm{~A}}$ or $A v \mathrm{PPIB}_{\mathrm{R} 43 \mathrm{~A}}$ and $A v$ dnaK or $A v \operatorname{lpxH}$. SDS-PAGE analysis of the elution fraction after the Ni-NTA purification of the $A \nu \mathrm{PPIB}_{\mathrm{F} 99 \mathrm{~A}}-A \nu \mathrm{dnaK}$ protein complex from E. coli BL21 (DE3) cells overexpressing $A v \mathrm{PPIB}_{\mathrm{F} 99 \mathrm{~A}}-A v$ dnaK-pCDFDuet1 (lane 1). SDS-PAGE analysis of the elution fraction after the Ni-NTA purification of the $A v \mathrm{PPIB}_{\mathrm{R} 43 \mathrm{~A}}-A v \mathrm{dnaK}$ protein complex from $E$. coli BL21 (DE3) cells overexpressing $A v \mathrm{PPIB}_{\mathrm{R} 43 \mathrm{~A}}-A v$ dnaK-pCDFDuet1 (lane 2). SDS-PAGE analysis of the elution fraction after the Ni-NTA purification of the $A v \mathrm{PPIB}_{\mathrm{F}_{99}}-A v l p x H$ protein complex from $E$. col BL21 (DE3) cells overexpressing $A v \mathrm{PPIB}_{\mathrm{F} 99 \mathrm{~A}}-A v$ lpxH-pCDFDuet1 (lane 3). SDS-PAGE analysis of the elution fraction after the $\mathrm{Ni}$ NTA purification of the $A \nu \mathrm{PPIB}_{\mathrm{R} 43 \mathrm{~A}}-A \nu \mathrm{lpxH}$ protein complex from E. coli BL21 (DE3) cells overexpressing $A v \mathrm{PPIB}_{\mathrm{R} 43 \mathrm{~A}}-A v l \mathrm{pxH}-$ pCDFDuet1 (lane 4).

volved in substrate binding of $H$. sapiens cypA [Kallen and Walkinshaw, 1992] were independently altered to Ala. The corresponding His-tagged proteins were overproduced in E. coli BL21 (DE3) cells and purified using Ni-NTA chromatography. $A v \mathrm{PPIB}_{\mathrm{F} 99 \mathrm{~A}}$ and $A \nu \mathrm{PPIB}_{\mathrm{R} 43 \mathrm{~A}}$ mutant proteins retained 1.7 and $1 \%$ of the catalytic efficiency of the wild-type enzyme, respectively, using the standard PPIase assay utilizing isomer-specific proteolysis by chymotrypsin [Kofron et al., 1991]. Further, both mutant proteins were not able to suppress thermal aggregation of citrate synthase when added in equimolar concentration to the assay mixture. However, they showed chaperone activity when they were added at 3- to 8-fold molar excess over citrate synthase (fig. $8 \mathrm{a}, \mathrm{b}$ ).

\section{$A v P P I B_{F 99 A}$ and $A v P P I B_{R 43 A}$ Point Mutants Still Interact with AvdnaK or AvlpxH while Their Remaining PPIase Activity Cannot Be Modulated by the Interaction}

In order to clarify the role of the PPIase activity on the binding of $A v \mathrm{PPIB}$ to $A v \mathrm{dnaK}$ or $A v \mathrm{lpxH}$, we tested whether $A v \mathrm{PPIB}_{\mathrm{F} 99 \mathrm{~A}}$ and $A v \mathrm{PPIB}_{\mathrm{R} 43 \mathrm{~A}}$ PPIase active site mutant proteins still interact with $A v$ dnaK or $A v \operatorname{lpxH}$ in vivo. We independently coexpressed $A \nu \mathrm{PPIB}_{\mathrm{F} 99 \mathrm{~A}}$ or $A v \mathrm{PPIB}_{\mathrm{R} 43 \mathrm{~A}}$ with $A v \mathrm{dnaK}$ or $A v \mathrm{lpxH}$, as two separate polypeptides, with a (His) ${ }_{6}$-tag fused at the N-terminus of $A v$ PPIB and an S-tag fused at the C-terminus of $A v \mathrm{dnaK}$ or $A v \mathrm{pxxH}$ using the pCDFDuet-1 vector. The soluble coexpressed proteins were purified under native conditions using Ni-resin affinity chromatography, indicating that each protein pair yet again forms a stable complex. The existence of both polypeptides was confirmed by SDS-PAGE and immunoblotting with antibodies against the His and S-tags (fig. 9). Control experiments were performed where just S-tag fused $A v \mathrm{dnaK}$ or $A v \operatorname{lpxH}$ were not retained by Ni-NTA agarose column. Any minor fractions of other molecular weights represent $E$. coli proteins retained by the $\mathrm{Ni}$-agarose since the elution fraction after the Ni-NTA purification using $E$. coli BL21 (DE3) cells overexpressing pCDFDuet-1 vector only was used as a control.

When we added $1 \times$ and $10 \times$ molar concentrations of $A v \mathrm{dnaK}$ or $A v \mathrm{lpxH}$ to the PPIase reaction containing $A v \mathrm{PPIB}_{\mathrm{F} 99 \mathrm{~A}}$ or $A v \mathrm{PPIB}_{\mathrm{R} 43 \mathrm{~A}}$, we did not observe a significant modulation of the already very low remaining activity of the active site mutants.

\section{Discussion}

Cyclophilins are characterized by PPIase activity that is implicated in protein folding and may function as molecular chaperones as well. To analyze whether A. vinelandii cyclophilins exhibit the functional characteristics of a cyclophilin, we determined the kinetic parameters of the two enzymes using Succinyl-Ala-Xaa-Pro-Phe-pNA tetrapeptides as substrates at $4{ }^{\circ} \mathrm{C}$. Both enzymes are characterized by kinetic parameters which are very similar. Compton et al. [1992] and Hayano et al. [1991] have also indicated that the activities of the two enzymes from E. coli are almost identical. Comparison of the catalytic efficiencies $\left(K_{\text {cat }} / K_{m}\right)$ of $A \nu$ PPIB and $A \nu$ PPIA with other PPIases revealed that the $K_{c a t} / K_{m}$ of $A$. vinelandii cyclophilins shows high similarity to other previously characterized cyclophilins [Compton et al., 1992; Hayano et al., 
1991]. Accordingly, it may be stated that both enzymes show enzymatic activities that are characteristic of cyclophilins. However, since the experiments for the determination of these catalytic parameters were performed at lower than physiological temperatures with artificial substrates, the $K_{c a t} / K_{m}$ values would not necessarily indicate the physiological properties of these PPIases.

There have been examples demonstrating a chaperoning function for classical PPIases, such as the eukaryotic Cyp-40 [Freeman et al., 1996], Cyp-20 [Rassow et al., 1995] and the prokaryotic trigger factor [Zarnt et al., 1997], SurA [Behrens et al., 2001], SlyD [Weininger et al., 2009], FkpA [Ramm and Plückthun, 2000], and Par27 [Hodak et al., 2008]. All these are multidomain proteins with most of the additional domains acting as chaperones and/or mediating the oligomerization of the protein [Saul et al., 2004]. The artificial introduction of the chaperone domain of SlyD into human FKBP12, which binds both peptides and protein substrates with a low affinity but a very high specificity with regard to the amino acid before the proline, created a folding enzyme that is virtually indistinguishable from the trigger factor with regard to substrate specificity and catalytic efficiency. Binding to the chaperone domains apparently overrides the inherent sequence specificity of the PPIase site and thus solves the problem of generic substrate recognition during protein folding [Jakob et al., 2009]. However, a single domain cyclophilin from Leishmania donovani has been shown to have an isomerase independent chaperone function [Chakraborty et al., 2002] and human single domain cyp18 holds chaperone activity as well [Moparthi et al., 2010]. Interestingly, A. vinelandii cytoplasmic cyclophilin, although not possessing additional chaperone domains, shows chaperone activity. Although AvPPIB active site mutants exhibit significantly reduced PPIase activity, they retain a considerable part of their chaperone activity implying that $A v$ PPIB's chaperoning site is at least partially functionally linked to its PPIase site.

Our gene expression analyses showed that $A v p p i B$ is expressed under various physiological and growth conditions, and is downregulated mainly by the stationary growth state. The growth on acetate increased about 1- to 3 -fold the relative expression ratio of $A v p p i B$, according to the source of ammonium supplied (endogenously or exogenously, respectively). Taken together, these data suggest that enzymes, directly or indirectly involved in acetate metabolism, may require the cyclophilin for modulation of their activity. AvppiA, on the other hand, shows a tendency for downregulation, indicating the limited necessity of the protein under the tested conditions and/or the probable requirement of the protein under specific but not yet identified physiological conditions. Knockout of the cytoplasmic ppiB caused strongly repressed swarming as revealed in a genome-wide screening of genes required for swarming motility in E. coli [Inoue et al., 2007]. Inactivation of the periplasmic PpiA from E. coli had no evident phenotype, significantly hindering the ability to identify specific protein substrates [Kleerebezem et al., 1995]. However, ppiB, a novel secreted PPIase from $L$. pneumophila, is necessary for optimal growth at low temperatures [Söderberg and Cianciotto, 2008], while in E. coli several molecular chaperones including ppiA were transiently induced upon cold shock [Kandror and Goldberg, 1997; Phadtare and Inouye, 2004], indicating a previously unidentified role of secreted peptidyl-prolyl cistrans isomerases in low temperature growth. Furthermore, ppiA is induced in response to periplasmic stresses such as unfolded proteins or elevated $\mathrm{pH}$ [Pogliano et al., 1997].

In an attempt to find natural substrates for the $A$. vinelandii cyclophilins, we performed a predictive analysis by searching the IntAct database for such protein interactions in various bacterial species, considering the proteins with cis-prolines to be a good starting point for our study. Searching the literature as well as the PDB database for homologous structures with cis-prolines, we noticed that in the structure of the substrate binding domain of dnaK from E. coli, Pro ${ }^{419}$ adopts the cis configuration [Wang et al., 1998]. Further, Vogel et al. [2006] proposed that Pro $^{143}$ in the ATPase domain constitutes a switch in mutual allosteric control between ATPase domain and the substrate binding domain of dnaK, likely involving a cis/trans transition. Therefore, we considered $A v d n a K$ as a good interacting candidate protein for $A \nu \mathrm{PPIB}$, and by coexpression of the two proteins we showed that they physically interact. This interaction was further verified by the observed stimulatory effect of $A v$ dnaK on the PPIase activity of $A \nu$ PPIB. Eukaryotic Cyp 40 appears to have an accessory role with heat shock protein Hsp90 in chaperone protein-folding machinery, essential for the activity of diverse intracellular signaling molecules [Duina et al., 1996; Nair et al., 1996], while it interacts with Hsc70 as well [Carrello et al., 2004]. It is important to further verify whether bacterial $A v$ PPIB regulates $A v$ dnaK in vivo and how this mechanism is used in conjunction with other known regulatory mechanisms or whether the two molecules act synergistically on protein folding.

Further, we found that the gene coding for a putative UDP-2, 3-diacylglucosamine hydrolase, located adjacent to Avppib, belongs to the calcineurin-like phosphoester- 
ase family (PF00149). Since immunophilins are able to interact with calcineurin in the absence of exogenous immunosupressive ligands and modulate its phosphatase activity [Cardenas et al., 1994], we hypothesized that such an interaction might be conserved among other members of the calcineurin-like phosphoesterase family as well. Considering $A v \mathrm{lpxH}$ as a probable interacting candidate protein for $A v \mathrm{PPIB}$, we coexpressed the two proteins and showed that they physically interact. UDP-2, 3-diacylglucosamine hydrolase is involved in lipid A biosynthesis catalyzing the pyrophosphate bond hydrolysis of the precursor UDP-2, 3-diacylglucosamine to yield 2, 3-diacylglucosamine 1-phosphate and UMP [Babinski et al., 2002]. This binding was further verified by the inhibitory effect of $A v$ lpxH on the PPIase activity of $A v$ PPIB, implying that $A v$ lpxH binds to the active site of $A v \mathrm{PPIB}$. The physiological meaning as well as the mechanism of such an interaction remains to be clarified.

In an attempt to clarify whether the PPIase activity of $A \nu \mathrm{PPIB}$ is required for these interactions, we separately introduced two active site point mutations to the enzyme which previously resulted in substantial reduction of enzymatic activity of human cypA as well [Zydowsky et al., 1992]. Both $A v$ PPIB mutant proteins lacked significant PPIase activity towards a synthetic tetrapeptide while they retained reduced levels of chaperone activity. When we coexpressed these mutant proteins with each of the interacting partners, we still observed an in vivo interaction probably due to the remaining chaperone activity of the active site mutant proteins. Their remaining minor PPIase activity could not be modulated by the interaction, indicating that the $A v$ PPIB PPIase activity may not be sufficient for dnaK or $\mathrm{lpxH}$ protein-protein interactions. Therefore, we speculate that the PPIase activity is at least partially involved in $A v$ PPIB in vivo function. Similarly, Drosophila main rhodopsin forms protein complexes rather than catalytic enzyme-substrate interactions with cyclophilin [Baker et al., 1994].

In summary, our study reveals that cytoplasmic and periplasmic A. vinelandii cyclophilins show in vitro PPIase activity, and cytoplasmic cyclophilin exhibits chaperone activity as well. Both proteins are monomeric based on gel filtration analyses. Using real-time RT-qPCR, we demonstrate that $A v p p i B$ is expressed under various physiological and growth conditions: mainly upregulated by the presence of acetate and downregulated on the stationary growth phase, while AvppiA shows a tendency for downregulation under the tested conditions. Further, we identified hsp70 chaperone protein dnaK and UDP-2, 3-diacylglucosamine hydrolase $\mathrm{lpxH}$ as potential interacting partners of the cytoplasmic cyclophilin and demonstrated their physical interaction by coexpression studies. An increase in $A v$ PPIB PPIase activity, in the presence of $A v \mathrm{dnaK}$ and a decrease in the presence of $A v \mathrm{lpxH}$, further confirms each interaction. However, the PPIase function does not seem to be essential for those interactions since $A v$ PPIB active site mutants still interact with dnaK and lpxH. Nevertheless, the exact function of cyclophilins in the bacterial physiology remains elusive, indicating the need for further structural and functional studies. Clearly, the mechanism as well as the physiological significance of the interaction of $A v$ PPIB with $A v$ dnaK and $A v l p x H$ needs to be determined while the identification of more natural cyclophilin substrates would link the catalytic properties of these enzymes with their physiological functions. At present, work towards these goals is under way.

\section{Experimental Procedures}

\section{Bacterial Strains and Growth Conditions}

E. coli XL-Bluel strain (Invitrogen) was used for the propagation of recombinant forms of the plasmid pET28a and pCDFDuet-1 (Novagen). E. coli strain BL21 (DE3) (Novagen) was used for the expression of recombinant proteins. All E. coli strains were grown in LB medium supplemented with kanamycin or streptomycin. A. vinelandii was grown at $30^{\circ} \mathrm{C}$ in Burk's nitrogenfree salts, supplemented with either glucose at $1 \%$ (BG) or sodium acetate at $0.3 \%$ (BA) and in Burk's salts supplemented with ammonium chloride at $0.1 \%$ and either glucose at $1 \%(\mathrm{BNG})$ or sodium acetate at $0.3 \%$ (BNA). Further, $A$. vinelandii was grown at $30^{\circ} \mathrm{C}$ in $\mathrm{LB}$ medium.

Heterologous Expression of AvPPIB and AvPPIA in E. coli and Purification of Recombinant Proteins

The coding sequence of AvppiB (YP_002799514) and the coding sequence of AvppiA (YP_002799096) without the first 33 amino acids which comprise the probable leader peptide were amplified using PCR with A. vinelandii genomic DNA as a template. The primers used were $A v$ PPIB-F: 5'-AAAGGATCCATCAAGCTGCAAACCAACCACG-3' with AvPPIB-R: 5'-AAACTCGAGTTATTCGACGATCTCGGCCTTC-3' and AvPPIA-F: 5'-AAAACATGTTAAAATCCCATGTCCTGCTGG-3' with AvPPIA-R: 5'-TTTCTCGAGGAGCTTTTTCGCCGAGGTGATC-3', carrying restriction sites for ligation to the $\mathrm{pET} 28 \mathrm{a}$ expression vector. The underlined nucleotides at each primer represent $\mathrm{BamHI}$, XhoI, PscI and XhoI, respectively. The fragments excised from amplified $A v p p i B$ and $A v p p i A$ sequences were cloned between the $B a m H I$ and XhoI sites of pET28a, resulting in $A v$ PPIB-pET28a, and between NcoI and XhoI sites of pET28a, resulting in AvPPIApET28a. The absence of undesired alterations was checked by nucleotide sequencing. Synthesis of recombinant proteins in E. coli BL21 (DE3) cells was initiated by addition of $0.5 \mathrm{~mm}$ isopropyl 
Table 2. Primers used in RT-qPCR reactions

\begin{tabular}{ll}
\hline Primer name & Nucleotide sequence \\
\hline Avin_23510-qPCR-F & 5'-ATCGGTGCCCTCGACCACTTCA-3' \\
Avin_23510-qPCR-R & 5'-ACGCCTTTCTCGACCACACTGC-3' \\
Avin_19090-qPCR-F & 5'-ATGAAGCCGGGGATGACCCGAT-3' \\
Avin_19090-qPCR-R & 5'-AGGCGCCGATCAGCGTGAAA-3' \\
Avin_38560-qPCR-F & 5'-TCCGGGTTGCCGAACATCACA-3' \\
Avin_38560-qPCR-R & 5'-TGCGCAAGATCACCGGCAACA-3' \\
\hline
\end{tabular}

1-thio- $\beta$-D-galactopyranoside when the culture reached $A_{600}$ of 0.6 and continued cultivation for an additional $4 \mathrm{~h}$ at $30^{\circ} \mathrm{C}$. Cells were harvested by centrifugation and were disrupted by sonication in lysis buffer $\left(50 \mathrm{mM} \mathrm{NaH}_{2} \mathrm{PO}_{4}, 300 \mathrm{mM} \mathrm{NaCl}, 10 \mathrm{mM}\right.$ imidazole supplemented with $1 \mathrm{mg} / \mathrm{ml}$ lysozyme). Cellular lysates were centrifuged and the supernatants were used for protein purification. Recombinant proteins were purified with Ni-NTA chromatography $\left(\mathrm{Ni}^{2+}\right.$-nitrilotriacetate, Qiagen) according to the manufacturer's instructions. To remove any imidazole and salts in the collected fractions, fractions were pooled accordingly and dialyzed against $35 \mathrm{~mm}$ Hepes buffer $\mathrm{pH}$ (8.0) and $70 \mathrm{~mm} \mathrm{NaCl}$, for $12 \mathrm{~h}$. The purity of the purified proteins was analyzed by $15 \%$ SDS-PAGE electrophoresis.

\section{Size Exclusion Chromatography}

Size exclusion chromatography was performed on a Prominence liquid chromatography system (Shimadzu Co., Tokyo, Japan) equipped with a ZORBAX GF-250 $4-\mu \mathrm{m}$ column $(4.6 \times 250$ $\mathrm{mm}$, Agilent Technologies, Palo Alto, Calif., USA) and a SPD 20A diode array detector. Aliquots of $20 \mu \mathrm{l}$ of protein samples were injected and eluted isocratically with $20 \mathrm{mM} \mathrm{Na}_{2} \mathrm{HPO}_{4}(\mathrm{pH} 7.0$ ), $130 \mathrm{mM} \mathrm{NaCl}$ at a flow rate of $1 \mathrm{ml} / \mathrm{min}$. Molecular weight calibration was performed using bovine thyroglobulin $(670 \mathrm{kDa})$, bovine $\gamma$-globulin (158 kDa), chicken ovalbumin (44 kDa), horse myoglobin $(17 \mathrm{kDa})$ and vitamin $\mathrm{B}_{12}(1.35 \mathrm{kDa})$ mixture, all components of the Bio-Rad gel filtration standard kit. Chromatograms were analyzed at $280 \mathrm{~nm}$.

\section{Peptidyl-Prolyl Cis/Trans Isomerase Enzymatic Assay}

To test whether $A v$ PPIB and $A v$ PPIA have PPIase activity, recombinant (His) ${ }_{6}-A v$ PPIB and (His) ${ }_{6}$ - $A v$ PPIA were expressed in and purified from E. coli BL21 (DE3), as described above. PPIase activity was tested with a chymotrypsin-coupled PPIase assay [Kofron et al., 1991], which is rate-limited by the cis/trans isomerization of the Xaa-Pro peptide bond of synthetic Suc-AXaaPFpNA (Bachem). The assay mixture contained $50 \mathrm{mM}$ Hepes buffer (pH 8.0) and $100 \mathrm{~mm} \mathrm{NaCl}, 50 \mu \mathrm{g} \alpha$-chymotrypsin (dissolved in $1 \mathrm{mM} \mathrm{HCl}$; Fluka), $25 \mu \mathrm{M}$ Suc-AXaaPF-pNA ( $5 \mathrm{mM}$ stock dissolved in trifluoroethanol supplemented with $0.45 \mathrm{M} \mathrm{LiCl}$ ), and the appropriate amount of enzyme. The assay buffer was mixed with $\alpha$-chymotrypsin and subsequently with the enzyme. The reaction was initiated inside the cuvette with the addition of the peptide and the increase in absorbance at $390 \mathrm{~nm}$ was monitored at $4{ }^{\circ} \mathrm{C}$ using a HITACHI U-2800 spectrophotometer equipped with a thermostated cell holder.

Biochemical Characterization of
Citrate Synthase Thermal Aggregation Assay

Thermal denaturation of citrate synthase $(0.25 \mu \mathrm{M}$ final concentration, Sigma) was achieved by incubation at $45^{\circ} \mathrm{C}$ in $40 \mathrm{~mm}$ Hepes ( $\mathrm{pH} 7.5$ ) for 15-20 min in the absence or in the presence of additional proteins, as previously described [Buchner et al., 1998]. Aggregation of citrate synthase was measured by monitoring the increase in turbidity at $500 \mathrm{~nm}$ in a HITACHI U-2800 spectrophotometer equipped with a thermostated cell holder. The recorded change in absorbance was due to the increase in light scattering upon aggregation of citrate synthase. Protein disulfide isomerase (Sigma) was used in positive control reactions and albumin (Research Organics) was used in negative control reactions.

\section{RNA Isolation}

Total RNA was isolated using a hot SDS/hot phenol method [Jahn et al., 2008]. Briefly, bacterial cultures were added to a $1 / 10$ volume of $95 \%$ ethanol plus $5 \%$ saturated phenol to stabilize cellular RNA and the cells were then harvested for 5 min at 6,000 rpm centrifugation at $4^{\circ} \mathrm{C}$. The supernatant was aspirated and the pellets were kept at $-80^{\circ} \mathrm{C}$ for no longer than 1 week. Pellets were resuspended in $800 \mu \mathrm{l}$ of lysis buffer $(10 \mathrm{mM}$ Tris- $\mathrm{HCl}(\mathrm{pH} 8.0)$ $1 \mathrm{mM}$ EDTA) and $3 \mathrm{mg} / \mathrm{ml}$ lysozyme. After the pellets were resuspended, $80 \mu \mathrm{l}$ of a $10 \%$ SDS solution was added and the lysate was mixed and incubated at $64^{\circ} \mathrm{C}$ for $2 \mathrm{~min}$. After incubation, $88 \mu \mathrm{l}$ of $1 \mathrm{M} \mathrm{NaOAc}$ (pH 5.2) was mixed with the lysate. To this solution, an equal volume of water-saturated phenol was added, mixed and incubated at $64^{\circ} \mathrm{C}$ for 6 min inverting the tubes several times. The samples were chilled on ice and centrifuged at 13,000 rpm for 10 $\min$ at $4^{\circ} \mathrm{C}$. The aqueous layer was transferred to a tube with equal volume of chloroform and centrifuged at 13,000 rpm for $5 \mathrm{~min}$ at $4^{\circ} \mathrm{C}$. The aqueous layer was ethanol precipitated by adding $1 / 10$ volume of $3 \mathrm{M} \mathrm{NaOAc}$ (pH: 5.2), $1 \mathrm{mM}$ EDTA and 2 volumes cold EtOH. The samples were incubated at $-80^{\circ} \mathrm{C}$ overnight. The RNA was pelleted by centrifugation at $13,000 \mathrm{rpm}$ for $25 \mathrm{~min}$ at $4^{\circ} \mathrm{C}$. Pellets were washed with ice cold $80 \% \mathrm{EtOH}$ and centrifuged at $13,000 \mathrm{rpm}$ for $5 \mathrm{~min}$ at $4^{\circ} \mathrm{C}$. The pellets were resuspended in a total of $100 \mu \mathrm{l}$ of RNase-free water.

Total RNA was quantified using microspectrophotometry (NanoDrop Technologies Inc.) and its quality was assessed by agarose gel electrophoresis. DNA was removed with DNase I (Promega). Removal of DNA from the RNA samples was confirmed by performing real-time PCR on 100 ng of total RNA using the Avin_38560-qPCR primer set (table 2), but without a reverse transcriptase step and those RNA samples found to yield $C_{t}$ values larger than 35 were judged to be sufficiently free of contaminating DNA for further analysis. Once more, total RNA was quantified using microspectrophotometry (NanoDrop Technologies) while the $A_{260} / A_{280}$ ratio was always above 2. Purified RNA was converted to cDNA immediately or stored frozen at $-80^{\circ} \mathrm{C}$.

\section{cDNA Synthesis}

First-strand cDNA synthesis was performed using Superscript II RT (Invitrogen). Briefly, $1.5 \mu \mathrm{g}$ of each RNA sample was reverse transcribed into cDNA. RNA was added to $1 \mu \mathrm{l}$ of $250 \mathrm{ng} / \mu \mathrm{lran}$ dom hexamer primers, $1 \mu \mathrm{l}$ of $10 \mathrm{mM}$ dNTP mix (Finnzymes) and RNase-free water to make $12 \mu \mathrm{l}$. The mixture was denatured at $65^{\circ} \mathrm{C}$ for $5 \mathrm{~min}$ and immediately chilled. $4 \mu \mathrm{l}$ of $5 \times$ first-strand buffer, $2 \mu \mathrm{l}$ of $0.1 \mathrm{M} \mathrm{DTT}, 1 \mu \mathrm{l}$ of 40 units/ $\mu \mathrm{l}$ RNaseOUT (Invitrogen) and $1 \mu \mathrm{l}$ of 200 units/ $\mu$ l SuperScript II (Invitrogen) was 
then added and the volume was adjusted to $20 \mu \mathrm{l}$. The mixture was incubated at $25^{\circ} \mathrm{C}$ for $10 \mathrm{~min}, 42^{\circ} \mathrm{C}$ for $50 \mathrm{~min}$ and finally $70^{\circ} \mathrm{C}$ for $15 \mathrm{~min}$ to inactivate the reaction.

\section{$R T-q P C R$}

The oligonucleotide primers used for RT-qPCR are listed in table 2. All primers were supplied by Invitrogen. The primers were designed using Primer-BLAST (http://blast.ncbi.nlm.nih.gov/ Blast.cgi) and optimized to an equal annealing temperature of $60^{\circ} \mathrm{C}$. Each primer pair was further assessed for specificity with melting curve analysis and gel electrophoresis of amplification products.

One microliter of diluted cDNA was added to the primer pair mix and SYBR Green Master Mix (Applied Biosystems) in each well. RT-qPCR was conducted on an MxPro Mx3005P PCR system and analyzed with MxPro v4.01 software (Stratagene). The PCR cycling conditions were $95^{\circ} \mathrm{C}$ for $10 \mathrm{~min}, 40$ cycles of $95^{\circ} \mathrm{C}$ for $30 \mathrm{~s}$ and $60^{\circ} \mathrm{C}$ for $1 \mathrm{~min}$; and $95^{\circ} \mathrm{C}$ for $1 \mathrm{~min}, 60^{\circ} \mathrm{C}$ for $30 \mathrm{~s}$ and $95^{\circ} \mathrm{C}$ for $30 \mathrm{~s}$. Plates were run for 40 cycles and fluorescence intensity was measured after every cycle. For each target sequence, the average cycle number at which fluorescence was detected above background in the exponential phase of amplification was obtained. No reverse transcription controls were included. The efficiency of each RT-qPCR reaction was calculated using the LinRegPCR software [Ruijter et al., 2009].

Relative expression of the target gene in the various Burk's minimal media versus LB full medium was calculated using the following equation, described by Pfaffl [2001]. Relative expression ratio per gene: $\mathrm{R}=\mathrm{E}_{\mathrm{GOI}}{ }^{\wedge}\left(\mathrm{C}_{\mathrm{t}} \text {, CONTROL }-\mathrm{C}_{\mathrm{t}, \text { SAMPLE }}\right)_{\mathrm{GOI}} / \mathrm{E}_{\mathrm{REF}} \wedge$ $\left(\mathrm{C}_{\mathrm{t}}\right.$, CONTROL - $\mathrm{C}_{\mathrm{t}}$, SAMPLE $)$ ReF. recA (Avin_38560) was used as internal control. Statistical significance was obtained by ANOVA followed by Tukey's multiple comparison test using GraphPad Prism v5.0 (GraphPad Software, San Diego, Calif., USA).

Heterologous Coexpression of AvPPIB with AvdnaK or AvlpxH in E. coli and Purification of Protein Complexes

$A \nu$ PPIB was coexpressed with $A v$ dnaK or $A v l p x H$ as two separate polypeptides with a $(\mathrm{His})_{6}$ tag fused at the $\mathrm{N}$-terminus of $A v \mathrm{PPIB}$ and an $\mathrm{S}$ tag fused at the C-terminus of $A v \mathrm{dnaK}$ or $A v \operatorname{lpxH}$, using the pCDFDuet-1 vector (Novagen). The primers used were $A v$ PPIB.H.Duet-F: 5'-AAAGGATCCAATCAAGCTGCAAACCAACCACG-3' with AvPPIB.H.Duet-R: 5'-AAAGCGGCCGCTTATTCGACGATCTCGGCCTTC- ${ }^{\prime}$, and Avdna K.S.Duet-F: 5'-GGGCATATGGGAAAAATCATCGGTATCGATC-3' with AvdnaK.S.Duet-R: 5'-AAACTCGAGCTTGTTGCCCTTGCTGTCCTTG-3', or AvlpxH.S.Duet-F: 5'-GGACATATGACCACACTGCTGATCTCGGATC- $3^{\prime}$ with AvlpxH.S. Duet-R: 5'-AAAGGTACCGTCGATGGGAAAGGGTGTCAGG$3^{\prime}$, carrying restriction sites for ligation to the pCDFDuet-1 expression vector. The underlined nucleotides at each primer represent BamHI, NotI, NdeI, XhoI, NdeI and KpnI, respectively. The fragments excised from amplified $A v p p i B$ and $A v d n a K$ or $A v l p x H$ sequences were cloned between the corresponding sites of pCDFDuet-1 or pACYCDuet-1, resulting in $A v$ PPIB- $A v$ dnaKpCDFDuet-1/pACYCDuet-1 and AvPPIB-AvlpxH-pCDFDuet-1/ pACYCDuet-1. The absence of undesired alterations was checked by nucleotide sequencing. E. coli BL21 (DE3) cells harboring the resulting vectors were grown at $30^{\circ} \mathrm{C}$ and induced with isopropyl 1-thio- $\beta$-D-galactopyranoside for $4 \mathrm{~h}$. The soluble coexpressed proteins were purified to high purity under native conditions by taking advantage of the His tag fused to $A v$ PPIB employing a Niresin column (Pierce). The purity of the protein complex was verified, and existence of both polypeptides was confirmed by SDSPAGE and immunoblotting with antibodies against the His and $S$ tags (Novagen), respectively.

Heterologous Expression of AvdnaK or AvlpxH in E. coli and Purification of Recombinant Proteins

The coding sequence of $A v d n a K$ (YP_002801394) and the coding sequence of $A v l p x H$ (YP_002799513) were amplified using PCR with $A$. vinelandii genomic DNA as a template. Both proteins were expressed with a (His) $)_{6}$ tag fused at their N-terminus. The primers used were AvdnaK.H.Duet-F: 5'-AAAGGATCCGGGAAAAATCATCGGTATCGATCTG-3' with Avdna K.H. Duet-R: 5'-AAAAAGCTTCTTGTTGCCC-TTGCTGTCCTTG ACC-3', or AvlpxH.H.Duet-F: 5'-AAAGGATCCGACCACACTGCTGATCTCGGATCTG-3' with AvlpxH.H.Duet-R: 5'AAGAAGCTTGTCGATGGGAAAGGGTGTCAGGTGG-3', carrying restriction sites for ligation to the pCDFDuet-1 expression vector. The underlined nucleotides represent $\mathrm{BamHI}$ at each forward primer and HindIII at each reverse primer. The fragments excised from amplified $A v d n a K$ and $A v l p x H$ sequences were cloned between the corresponding sites of pCDFDuet-1, resulting in $A v$ dnaK-pCDFDuet-1 and AvlpxH-pCDFDuet-1. The absence of undesired alterations was checked by nucleotide sequencing. Protein expression and purification was performed as described above.

\section{Site-Directed Mutagenesis of $A v P P I B$}

F99A and R43A point mutations were engineered using the gene-SOEing method described by Horton [1995]. The primers used were $A v$ PPIB.Duet-F with $A v$ PPIB $_{\text {F99A }}-\mathrm{R}$ : $5^{\prime}$-GTCCTTGACGTTGATTGCGAACTGCGCGCTGG-3' or $A v \mathrm{PPIB}_{\mathrm{R} 43 \mathrm{~A}^{-\mathrm{R}}}$ : 5'-GAAGCCGTCGATCACTGCGTGGAAGATGGTGC-3' and A $v$ PPIB $_{\text {F99A }}$-F: 5'-CCAGCGCGCAGTTCGCAATCAACGTCAAGGAC-3' or $A \nu \mathrm{PPIB}_{\mathrm{R} 43 \mathrm{~A}}-\mathrm{F}$ : 5'-GCACCATCTTCCACGCAGTGATCGACGGCTTC-3' with AvPPIB.Duet-R. Nucleotides encoding mutated amino acids are underlined. The primary PCR products were purified and then used as templates for the second round of PCR. The final products were digested with restriction enzymes corresponding to the cleavage sites introduced via PCR and ligated into appropriately digested pCDFDuet-1 expression vector, resulting in $A v \mathrm{PPIB}_{\mathrm{F} 99 \mathrm{~A}}-\mathrm{pCDFDuet}-1$ and $A v \mathrm{PPIB}_{\mathrm{R}_{43} \mathrm{~A}^{-}}$ pCDFDuet-1. The absence of undesired alterations was checked by nucleotide sequencing. Protein expression and purification was performed as described above. 


\section{References}

Arifuzzaman M, Maeda M, Itoh A, Nishikata K, Takita C, Saito R, Ara T, Nakahigashi K, Huang HC, Hirai A, Tsuzuki K, Nakamura $\mathrm{S}$, Altaf-Ul-Amin M, Oshima T, Baba T, Yamamoto N, Kawamura T, Ioka-Nakamichi T, Kitagawa M, Tomita M, Kanaya S, Wada C, Mori H: Large-scale identification of protein-protein interaction of Escherichia coli K-12. Genome Res 2006;16:686-691.

- Babinski KJ, Ribeiro AA, Raetz CR: The Escherichia coli gene encoding the UDP-2, 3-diacylglucosamine pyrophosphatase of lipid A biosynthesis. J Biol Chem 2002;277:2593725946.

Baker EK, Colley NJ, Zuker CS: The cyclophilin homolog NinaA functions as a chaperone, forming a stable complex in vivo with its protein target rhodopsin. EMBO J 1994;13: 4886-4895.

-Baum N, Schiene-Fischer C, Frost M, Schumann M, Sabapathy K, Ohlenschläger O, Grosse F, Schlott B: The prolyl cis/trans isomerase cyclophilin 18 interacts with the tumor suppressor $\mathrm{p} 53$ and modifies its functions in cell cycle regulation and apoptosis. Oncogene 2009;28:3915-3925.

-Behrens S, Maier R, de Cock H, Schmid FX, Gross CA: The SurA periplasmic PPIase lacking its parvulin domains functions in vivo and has chaperone activity. EMBO J 2001;20:285-294.

- Braaten D, Luban J: Cyclophilin A regulates HIV-1 infectivity, as demonstrated by gene targeting in human T cells. EMBO J 2001;20: 1300-1309.

- Buchner J, Grallert H, Jakob U: Analysis of chaperone function using citrate synthase as a nonnative substrate. Methods Enzymol 1998;290:323-338.

Butland G, Peregrín-Alvarez JM, Li J, Yang W, Yang X, Canadien V, Starostine A, Richards D, Beattie B, Krogan N, Davey M, Parkinson J, Greenblatt J, Emili A: Interaction network containing conserved and essential protein complexes in Escherichia coli. Nature 2005; 433:531-537.

-Cardenas ME, Hemenway C, Muir RS, Ye R, Fiorentino D, Heitman J: Immunophilins interact with calcineurin in the absence of exogenous immunosuppressive ligands. EMBO J 1994;13:5944-5957.

- Carrello A, Allan RK, Morgan SL, Owen BA, Mok D, Ward BK, Minchin RF, Toft DO, Ratajczak T: Interaction of the Hsp90 cochaperone cyclophilin 40 with Hsc70. Cell Stress Chaperones 2004;9:167-181.

-Chakraborty A, Das I, Datta R, Sen B, Bhattacharyya $D$, Mandal C, Datta AK: A single-domain cyclophilin from Leishmania donovani reactivates soluble aggregates of adenosine kinase by isomerase-independent chaperone function. J Biol Chem 2002;277:4745147460 .
Chenna R, Sugawara H, Koike T, Lopez R, Gibson TJ, Higgins DG, Thompson JD: Multiple sequence alignment with the Clustal series of programs. Nucleic Acids Res 2003;31:34973500.

Compton LA, Davis JM, Macdonald JR, Bächinger HP: Structural and functional characterization of Escherichia coli peptidyl-prolyl cis-trans isomerases. Eur J Biochem 1992; 206:927-934.

Duina AA, Chang HC, Marsh JA, Lindquist S, Gaber RF: A cyclophilin function in Hsp90dependent signal transduction. Science 1996;274:1713-1715.

Fischer G, Bang H, Mech C: Determination of enzymatic catalysis for the cis-trans-isomerization of peptide binding in proline-containing peptides. Biomed Biochim Acta 1984;43:1101-1111.

Freeman BC, Toft D, Morimoto RI: Molecular chaperone machines: chaperone activities of the cyclophilin CyP-40 and the steroid aporeceptor associated protein $\mathrm{p} 23$. Science 1996;274:1718-1720.

- Galat A: Peptidyl prolyl cis/trans isomerases (immunophilins): biological diversity-targetsfunctions. Curr Top Med Chem 2003;3: 1315-1347.

Göthel SF, Marahiel MA: Peptidyl-prolyl cistrans isomerases, a superfamily of ubiquitous folding catalysts. Cell Mol Life Sci 1999; 55:423-436.

Göthel SF, Scholz C, Schmid FX, Marahiel MA: Cyclophilin and trigger factor from Bacillus subtilis catalyze in vitro protein folding and are necessary for viability under starvation conditions. Biochemistry 1998;37:1339213399.

Hayano T, Takahashi N, Kato S, Maki N, Suzuki M: Two distinct forms of peptidyl prolyl-cistrans-isomerase are expressed separately in periplasmic and cytoplasmic compartments of Escherichia coli cells. Biochemistry 1991; 30:3041-3048.

-Hermjakob H, Montecchi-Palazzi L, Lewington C, Mudali S, Kerrien S, Orchard S, Vingron M, Roechert B, Roepstorff P, Valencia A, Margalit H, Armstrong J, Bairoch A, Cesareni G, Sherman D, Apweiler R: IntAct: an open source molecular interaction database. Nucleic Acids Res 2004;32:D452-D455.

Hodak H, Wohlkönig A, Smet-Nocca C, Drobecq $\mathrm{H}$, Wieruszeski JM, Senechal M, Landrieu I, Locht C, Jamin M, Jacob-Dubuisson F: The peptidyl-prolyl isomerase and chaperone Par27 of Bordetella pertussis as the prototype for a new group of parvulins. J Mol Biol 2008;376:414-426.

Horton RM: PCR-mediated recombination and mutagenesis. SOEing together tailor-made genes. Mol Biotechnol 1995;3:93-99.

- Inoue T, Shingaki R, Hirose S, Waki K, Mori H, Fukui K: Genome-wide screening of genes required for swarming motility in Escherichia coli K-12. J Bacteriol 2007;189:950-957.
Jabs A, Weiss MS, Hilgenfeld R: Non-proline Cis peptide bonds in proteins. J Mol Biol 1999; 286:291-304.

-Jahn CE, Charkowski AO, Willis DK: Evaluation of isolation methods and RNA integrity for bacterial RNA quantitation. J Microbiol Methods 2008;75:318-324.

- Jakob RP, Zoldák G, Aumüller T, Schmid FX: Chaperone domains convert prolyl isomerases into generic catalysts of protein folding. Proc Natl Acad Sci USA 2009;106:2028220287.

Jaschke A, Mi H, Tropschug M: Human T cell cyclophilin 18 binds to thiol-specific antioxidant protein Aop1 and stimulates its activity. J Mol Biol 1998;277:763-769.

Kallen J, Walkinshaw MD: The X-ray structure of a tetrapeptide bound to the active site of human cyclophilin A. FEBS Lett 1992;300: 286-290.

Kandror O, Goldberg AL: Trigger factor is induced upon cold shock and enhances viability of Escherichia coli at low temperatures. Proc Natl Acad Sci USA 1997;94:4978-4981.

-Kleerebezem M, Heutink M, Tommassen J: Characterization of an Escherichia coli rotA mutant, affected in periplasmic peptidylprolyl cis/trans isomerase. Mol Microbiol 1995; 18:313-320.

Kofron JL, Kuzmic P, Kishore V, Colon-Bonilla E, Rich DH: Determination of kinetic constants for peptidyl prolyl cis-trans isomerases by an improved spectrophotometric assay. Biochemistry 1991;30:6127-6134.

-Konno M, Sano Y, Okudaira K, Kawaguchi Y, Yamagishi-Ohmori Y, Fushinobu S, Matsuzawa H: Escherichia coli cyclophilin B binds a highly distorted form of trans-prolyl peptide isomer. Eur J Biochem 2004;18:3794-3803.

Lee SP, Hwang YS, Kim YJ, Kwon KS, Kim HJ, Kim K, Chae HZ: Cyclophilin A binds to peroxiredoxins and activates its peroxidase activity. J Biol Chem 2001;276:29826-29832.

Liu J, Walsh CT: Peptidyl-prolyl cis-trans-isomerase from Escherichia coli: a periplasmic homolog of cyclophilin that is not inhibited by cyclosporin A. Proc Nat Acad Sci USA 1990; 87:4028-4032.

-Manteca A, Kamphausen T, Fanghanel J, Fischer G, Sanchez J: Cloning and characterization of a Streptomyces antibioticus ATCC11891 cyclophilin related to Gram negative bacteria cyclophilins. FEBS Lett 2004;572:19-26.

Marks AR: Cellular functions of immunophilins. Physiol Rev 1996;76:631-649.

- Moparthi SB, Fristedt R, Mishra R, Almstedt K, Karlsson M, Hammarström P, Carlsson U: Chaperone activity of Cyp18 through hydrophobic condensation that enables rescue of transient misfolded molten globule intermediates. Biochemistry 2010;49:1137-1145.
Biochemical Characterization of Azotobacter vinelandii Cyclophilins 
-Nair SC, Toran EJ, Rimerman RA, Hjermstad S, Smithgall TE, Smith DF: A pathway of multichaperone interactions common to diverse regulatory proteins - estrogen receptor, Fes tyrosine kinase, heat shock transcription factor, HSF1, and the aryl hydrocarbon receptor. Cell Stress Chaperones 1996;1:237-250.

-Pahl A, Gewies A, Keller U: ScCypB is a novel second cytosolic cyclophilin from Streptomyces chrysomallus which is phylogenetically distant from ScCypA. Microbiology 1997: $143 ; 117-126$.

- Pahl A, Uhlein M, Bang H, Schlumbohm W, Keller U: Streptomycetes possess peptidylprolyl cis-trans isomerases that strongly resemble cyclophilins from eukaryotic organisms. Mol Microbiol 1992;6:3551-3558.

-Pfaffl MW: A new mathematical model for relative quantification in real-time RT-PCR. Nucleic Acids Res 2001;29:e45.

- Phadtare S, Inouye M: Genome-wide transcriptional analysis of the cold shock response in wild-type and cold-sensitive, quadruplecsp-deletion strains of Escherichia coli. J Bacteriol 2004;186:7007-7014.

-Pissavin C, Hugouvieux-Cotte-Pattat N: Characterization of a periplasmic peptidyl-prolyl cis-trans isomerase in Erwinia chrysanthemi. FEMS Microb Lett 1997;157:59-65.

Pogliano J, Lynch AS, Belin D, Lin EC, Beckwith J: Regulation of Escherichia coli cell envelope proteins involved in protein folding and degradation by the Cpx two-component system. Genes Dev 1997;11:1169-1182.

Ramm K, Plückthun A: The periplasmic Escherichia coli peptidyl-prolyl cis, trans-Isomerase FkpA II. Isomerase-independent chaperone activity in vitro. J Biol Chem 2000;275: 17106-17113.
Rassow J, Mohrs K, Koidl S, Barthelmess IB, Pfanner N, Tropschug M: Cyclophilin 20 is involved in mitochondrial protein folding in cooperation with molecular chaperones Hsp70 and Hsp60. Mol Cell Biol 1995;15: 2654-2662.

Ruijter JM, Ramakers C, Hoogaars WM, Karlen Y, Bakker O, van den Hoff MJ, Moorman AF: Amplification efficiency: linking baseline and bias in the analysis of quantitative PCR data. Nucleic Acids Res 2009;6:e45.

Saul FA, Arié JP, Vulliez-le Normand B, Kahn R, Betton JM, Bentley GA: Structural and functional studies of FkpA from Escherichia coli, a cis/trans peptidyl-prolyl isomerase with chaperone activity. J Mol Biol 2004;335:595608.

Schiene-Fischer C, Yu C: Receptor accessory folding helper enzymes: the functional role of peptidyl prolyl cis/trans isomerases. FEBS Lett 2001;495:1-6.

Schmid FX: Prolyl isomerase: enzymatic catalysis of slow protein-folding reactions. Annu Rev Biophys Biomol Struct 1993;22:123-142.

-Schmidt B, Tradler T, Rahfeld JU, Ludwing B, Jain B, Mann K, Rücknagel KP, Janowski B, Schierhorn A, Küllertz G, Hacker J, Fischer G: A cyclophilin-like peptidyl-prolyl cis/ trans isomerase from Legionella pneumophi$l a$ - characterization, molecular cloning and over expression. Mol Microbiol 1996;21: 1147-1160.
$>$ Schönbrunner ER, Mayer S, Tropschug M, Fischer G, Takahashi N, Schmid FX: Catalysis of protein folding by cyclophilins from different species. J Biol Chem 1991;266: 3630-3635.

-Söderberg MA, Cianciotto NP: A Legionella pneumophila peptidyl-prolyl cis-trans isomerase present in culture supernatants is necessary for optimal growth at low temperatures. Appl Environ Microbiol 2008;74: 1634-1638.

Vogel M, Bukau B, Mayer MP: Allosteric regulation of Hsp70 chaperones by a proline switch. Mol Cell 2006;21:359-367.

-Wang H, Kurochkin AV, Pang Y, Hu W, Flynn GC, Zuiderweg ER: NMR solution structure of the $21-\mathrm{kDa}$ chaperone protein DnaK substrate binding domain: a preview of chaperone-protein interaction. Biochemistry 1998; 37:7929-7940.

-Weininger U, Haupt C, Schweimer K, Graubner W, Kovermann M, Brüser T, Scholz C, Schaarschmidt P, Zoldak G, Schmid FX, Balbach J: NMR solution structure of SlyD from Escherichia coli: spatial separation of prolyl isomerase and chaperone function. J Mol Biol 2009;387:295-305

-Zarnt T, Tradler T, Stoller G, Scholz C, Schmid FX, Fischer G: Modular structure of the trigger factor required for high activity in protein folding. J Mol Biol 1997;271:827-837.

Zydowsky LD, Etzkorn FA, Chang HY, Ferguson SB, Stolz LA, Ho SI, Walsh CT: Active site mutants of human cyclophilin A separate peptidyl-prolyl isomerase activity from cyclosporin A binding and calcineurin inhibition. Protein Sci 1992;1:1092-1099. 